\title{
EDUKASI KAPABILITAS KELUARGA DALAM PEMBELAJARAN DI MASA PANDEMI COVID-19 DI BANTEN
}

\author{
Dewi Surani ${ }^{1)}$, Muhammad Bayi Tabrani' ${ }^{2)}$ \\ ${ }^{1,2}$ Program Studi Pendidikan Teknologi Informasi, Fakultas Ilmu Pendidikan, Universitas Bina Bangsa
}

\begin{abstract}
Abstrak
Kondisi pandemic Covid-19 dan berlanjut New Normal menuntut orang tua menyiapkan diri sebaik mungkin dalam pelaksanaannya agar kegiatan pembelajaran bisa berjalan optimal, oleh karena itu dibutuhkan edukasi mengenai kapabilitas keluarga.Kegiatan pengabdian masyarakat ini diadakan dalam bentuk Webinar melalui aplikasi Zoom dalam pada tanggal 27 Juni 2020 berupa penyuluhan, paparan materi mengenai kapabilitas keluarga dalam pembelajaran di masa pandemi. Kegiatan pengabdian ini bertujuan memberikan edukasi kepada masyarakat mengenai perlindungan anak dari perspektif pendidikan di Era New Normal dilihat dari kapabilitas keluarga. Dengan adannya kegiatan edukasi ini diharapkan masyarakat mendapatkan wawasan dan edukasi dalam menghadapi pembelajaran online dan bisa mendampingi putra-putrinya agar lebih optimal dalam pembelajaran daring sehingga tercipta kegiatan pembelajaran yang efektif dan tercapai tujuan pembelajaran.
\end{abstract}

Kata Kunci: kapabilitas, keluarga, pendidikan, pandemi

\begin{abstract}
The condition of the Covid-19 pandemic and the continuing New Normal requires parents to prepare themselves as best as possible in its implementation so that learning activities can run optimally, therefore education is needed regarding family capabilities. This community service activity was held in the form of a Webinar through the Zoom application on June 272020 in the form of counseling, material exposure regarding family capabilities in learning during a pandemic. This service activity aims to provide education to the public about child protection from an educational perspective in the New Normal Era seen from family capabilities. With the existence of this educational activity, it is hoped that the community will gain insight and education in the face of online learning and can accompany their children to be more optimal in online learning so that effective learning activities can be achieved and learning objectives are achieved.
\end{abstract}

Keywords: capability, family, education, pandemic 


\section{PENDAHULUAN}

Situasi pandemi Covid-19 yang terjadi saat ini telah merubah semua elemen kehidupan terutam dalam bidang pendidikan. Semua pihak baik guru, siswa bahkan orang tua dituntut supaya membiasakan diri melakukan pembelajaran secara daring dengan pemanfaatan teknologi dalam pembelajaran. Dalam pelaksanaanya, pembelajaran daring di rumah selama pandemic Covid-19, dimaknai sebagai kegiatan memindahkan belajar di sekolah ke rumah dengan berbagai platform. Selain itu juga masalah quota internet menjadi masalah bagi guru dan orang orang tua siswa (Prodjo, 2020).

Melihat data dari Kementerian Pendidikan dan Kebudayaan, per tanggal 13 April 2020, sebanyak 68.729.037 murid belajar dirumah dengan metode pembelajaran jarak jauh di Indonesia, yang tentu saja banyak kendala dan keterbatasan yang dirasakan oleh guru, orang tua dan anak dalam proses belajar.

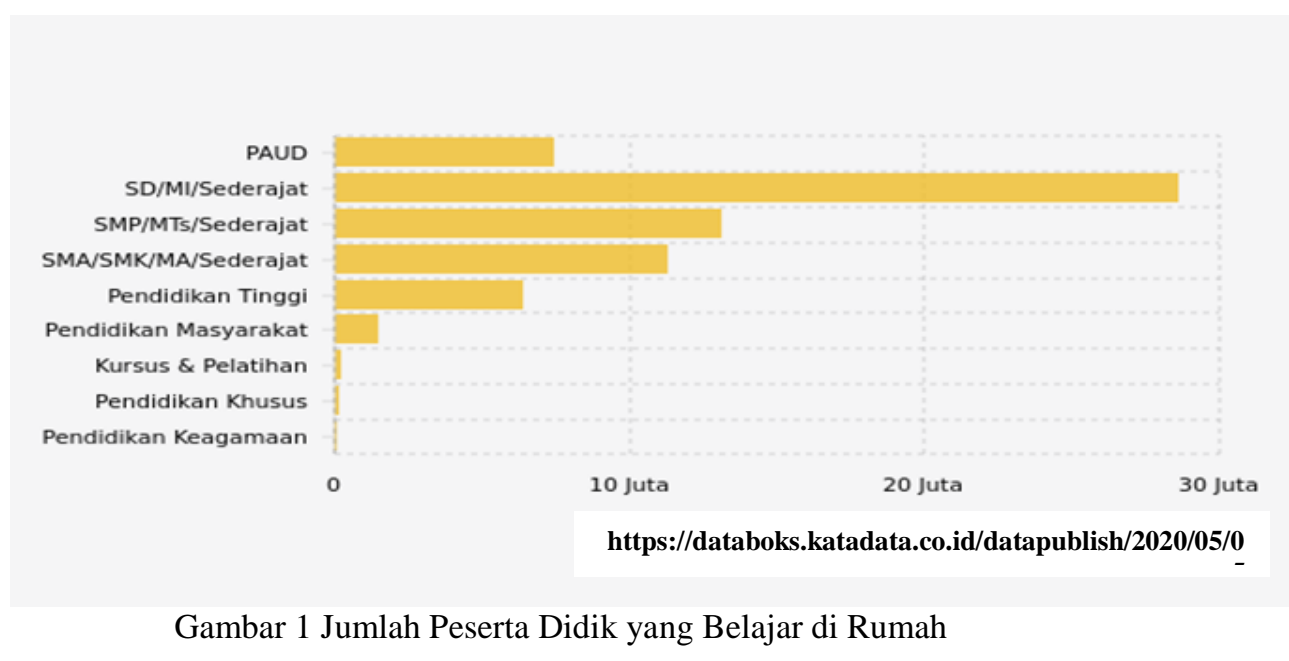

Dalam pembelajaran jarak jauh dengan banyak kendala dalam pelaksanaannya membutuhkan dukungan seperti keaktifan dan mental orang tua, kompetensi guru serta saran fasilitas IT. Dalam pembelajaran jarak jauh di masa pandemi saat orang tua harus menyadari betul bahwa orang tua bertanggung jawab sepenuhnya terhadap pendidikan anak sesuai dengan kodratnya bahwa orang merupakan pendidik pertama dan utama, (Amanah, 2020). Faktor pendukung lainnya adalah terciptanya atmosfir keluarga dapat memberikan pengaruh kepada ketahanan keluarga. Menciptakan saling empati di dalam keluarga dan saling menghargai, seperti memberikan perhatian dengan mendengarkan yang mendalam, berbicara penuh cinta guna membangun komunikasi. Kebagian akan tercipta ketika ada komunikasi dan pengertian diantara anggota keluarga.(Hanh, 2007).

Banyak peran yang harus lebih memaksimalkan perannya agar proses belajar dapat lebih maksimal antara lain peran orang tua dan juga pendidik. Kapabilitas atau kompetensi dari keluarga dan pendidik sangat dibutuhkan dalam mendukung pembelajran di era New Normal ini, akan tetapi masih rendahnya kapabilitas hal ini terlihat dari problema yang muncul dalam pembelajaran daring, sehingga perlu diadakannya edukasi guna memeberikan wawasan sehinga diharapkannya adanya kapabilitas tersebut. Karena pada dasarnya keluarga merupakan termpat terbaik bagi poses pendidikan anak. Guru terbaik bagi anak adalah orang tua.(Amanah, 2020) 
Guna memaksimalkan peran keluarga dalam pembelajaran jarak jauh maka ketahanan keluarga harus ditingkatkan. Pendidikan berbasis keluarga menjadi solusi yang tepat, walaupun selama ini orang tua menganggap ruang kelas hal utama dalam proses pendidikan anak, sepenuhnya proses itu dibebankan kepada guru dan praktisi Pendidikan yang ada di sekolah. Namun di saat pandemic Covid 19 saat ini sepenuhnya dikembalikan kepada orang tua selaku pendidik pertama dan utama bagi anak. Kapabilitas berarti kompentensi. Akan tetapi makana dari kapabiloitas lebih dari hanya ketrampilan (skill) saja, kapabilitas berarti lebih [aham secara mendetail sehingga sungguh-sungguh menguasai kemampuannya muoai dari titik kelemahannya. (KBBI.2014). Kapabilitas merupakan kumpulan ketrampilan yang lebih sepesifik, prosedur dan proses yang dapat dimanfaatkan sumber daya ke keunggulan kompetitif.(Baker\&Sinkula.2005). Berdasarkan pengertian kapabilitas yang telah diungkapkan, maka dapat didefinisasikan sebagai sebuah kemampuan yang memiliki lebih dari hanya keterampilan pada suatu hal yang menjadi keunggulan bersaing dan menguasai kemampuan dari titik kelemahan.

Ketahanan keluarga mencakup tiga indikator, yaitu (1)ketahanan fisik yang berdasarkan nilai dan fungsi keluarga berkaitan dengan kemampuan ekonomi keluarga dalam memperoleh sumber ekonomi untuk mencukupi kebutuhan dasar keluarga, (2) ketahanan sosial yang meliputi penerapan norma dan nila agama di keluarga, terjaganya ikatan dan komitmen serta komunikasi antar anggota keluarga, berbagi peran, penetapan tujuan dan dorongan untuk maju menjadi kekuataan keluarga dalam menghadapi tantangan dan masalah keluarga, (3) dan ketahanan psikologis yang mmerupakan kemampuan anggota keluarga dalam mengelola emosi sehingga menghasilkan komsep serta kepribadian yang positif.(Amalia, 2018).

Dilihat dari gambaran situasi yang telah dipaparkan di bagian pendahuluan maka bisa dirumuskan permasalahan yang muncul dalam pelaksanaan pendidikan yang muncul pada era New Normal khususnya antara lain kurangnya kapabilitas keluarga dalam mendukung pelaksanaan proses pembelajaran di era New Normal, sehingga perlu diberikan edukasi yang bertujuan menambah wawaasan dan meningkatlan kapabilitas keluarga guna menciptakan pembelajaran daring yang optimal guna mencapai tujuan pendidikan.

\section{METODE PELAKSANAAN}

Pelaksanaan kegiatan pengabdian masyarakat ini merupakan kegiatan pengabdian masyarakat collaborating dengan Lembaga Perlindungan Anak (LPA) Banten, tempat dan waktu disesuaikan dengan situasi, karena mengingat masa pandemic masih berlangsung, maka kegiatan pengabdian dilaksanakan secara online melalui aplikasi zoom meeting dalam bentuk Webinar. Sasaran kegiatan pengabdian ini ialah masyarakat umum/publik, orang tua, akademisi, mahasiswa dan pemangku kebijakan yang ada di wilayah Banten, dengan total keseluruhan peserta berjumlah 102 peserta. 


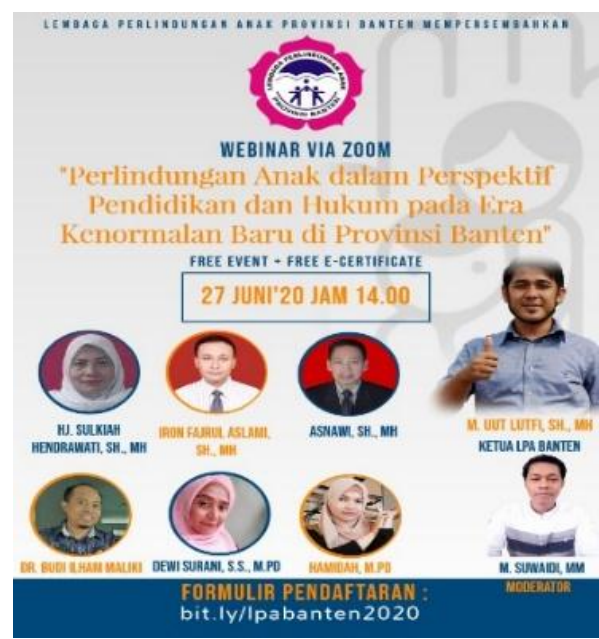

Gambar 2 Flyer Webinar Kegiatan Pengabdian Masyarakat

Waktu pelaksanaan kegiatan pengabdian masyarakat ini diadakan pada tanggl 27 Juni 2020 mulai pukul 14.00 - 16.30 WIB. Kegiatan pengabdian di Webinar berisikan materi edukasi penguatan perlindungan anak dilihat dari perspektif pendidikan di masa pandemi Covid-19, difokuskan pada kapabilitas keluarga dalam mendukung menghadapi pembelajaran online di masa Pandemi Covid-19.

Berikut rincian pelaksanaan kegiatan pengabdian Masyrakat:

Tabel 1 Jadwal Kegiatan Pengabdian Masyarakat

\begin{tabular}{|c|c|c|c|c|}
\hline No & Pukul & Kegiatan & Pelaksana & Keterangan \\
\hline 1. & $14.00-14.05 \mathrm{WIB}$ & Pembukaan & Jaka Wijaya Kusuma, M.Pd & Host \\
\hline \multirow[t]{2}{*}{2.} & \multirow[t]{2}{*}{ 14.05-14.20 WIB } & \multirow[t]{2}{*}{ Sambutan } & M. Uut Lutfi, SH., MH & Ketua LPA Banten \\
\hline & & & $\begin{array}{l}\text { Hj Sulkiah Hendrawati., } \\
\text { SH.,MH }\end{array}$ & $\begin{array}{l}\text { Dekan Fakultas } \\
\text { Hukum Uniba }\end{array}$ \\
\hline 3. & 14.20.14-30 WIB & $\begin{array}{l}\text { Persiapan } \\
\text { Penjelasan Materi } \\
\text { dan Pengenalan } \\
\text { Narasumber }\end{array}$ & Moh. Suwaidi, S.Pd.I, MM & Moderator \\
\hline \multirow[t]{3}{*}{4.} & \multirow[t]{3}{*}{ 14.30-15.15 WIB } & \multirow{3}{*}{$\begin{array}{l}\text { Materi I: } \\
\text { Perlindungan Anak } \\
\text { dalam Perspektif } \\
\text { Pendidika }\end{array}$} & $\begin{array}{l}\text { Metode Pembelajaran yang } \\
\text { Efektif dalam membentuk } \\
\text { karakter anak : Hamidah, M.Pd }\end{array}$ & Narasumber \\
\hline & & & $\begin{array}{l}\text { - Kapabilitas orang tua dan } \\
\text { pendidik dalam pembelajaran : } \\
\text { Dewi Surani, M.Pd \& M Bayi } \\
\text { Tabrani }\end{array}$ & Narasumber \\
\hline & & & $\begin{array}{l}\text { - Transisi Mental Pedagogik } \\
\text { Pada Anak Pasca Pandemic. : } \\
\text { Dr. Budi Ilham Maliki } \\
\text { S.Pd,.MM }\end{array}$ & Narasumber \\
\hline \multirow[t]{2}{*}{5.} & \multirow[t]{2}{*}{ 15.15-16.00 WIB } & \multirow{2}{*}{$\begin{array}{l}\text { Materi II: } \\
\text { Perlindungan Anak } \\
\text { dalam Perspektif } \\
\text { Hukum }\end{array}$} & $\begin{array}{l}\text { Aspek Kebijakan Pemerintah } \\
\text { Daerah : Asnawi, SH., MH }\end{array}$ & Narasumber \\
\hline & & & $\begin{array}{l}\text { Aspek Kriminologi dan SPPA : } \\
\text { Iron Fajrul Aslami, SH., MH }\end{array}$ & Narasumber \\
\hline 6. & 16.00-16.20 WIB & Sesi Tanya Jawab & Moh. Suwaidi, S.Pd.I, MM & Moderator \\
\hline 7. & 16.20-16.30 WIB & Penutup & Jaka Wijaya Kusuma, M.Pd & Host \\
\hline
\end{tabular}




\section{HASIL DAN PEMBAHASAN}

Keberhasilan dalam belajar daring dirumah di masa pandemi salah satunya dipengaruhi oleh faktor eksternal yaitu keluarga khususnya orang tua. Hal ini juga didukung penelitian yang dilakukan Darwin Bangun bahwa perhatian yang diberikan orang tua waktu belajar di rumah menentukan prestasi anak. Akan tetapi di sayangkan kurangnya perhatian orang tua dalam pendidikan anaknya (Bangun, 2012). Apalagi di masa Pandemi Covid-19 yang menuntut pembelajaran tetap berjalan meskipun pelaksanaannya secara daring dari rumah.

Kesiapan kemampuan yang dimiliki orang tua meliputi fasilitas dirumah, siapanmental ornag tua dan anak serta keaktifan orang tua dalam mendampingi proses pembelajaran jarak jauh menjadi salah satu penentu. Selain itu pihak lain seperti guru yang aktif berkomunikasi dan memberikan pendampingan selama proses pembelajaran serta tersediannya fasilitas juga sangat mendukung suksesnya pembelajaran jarak jauh.

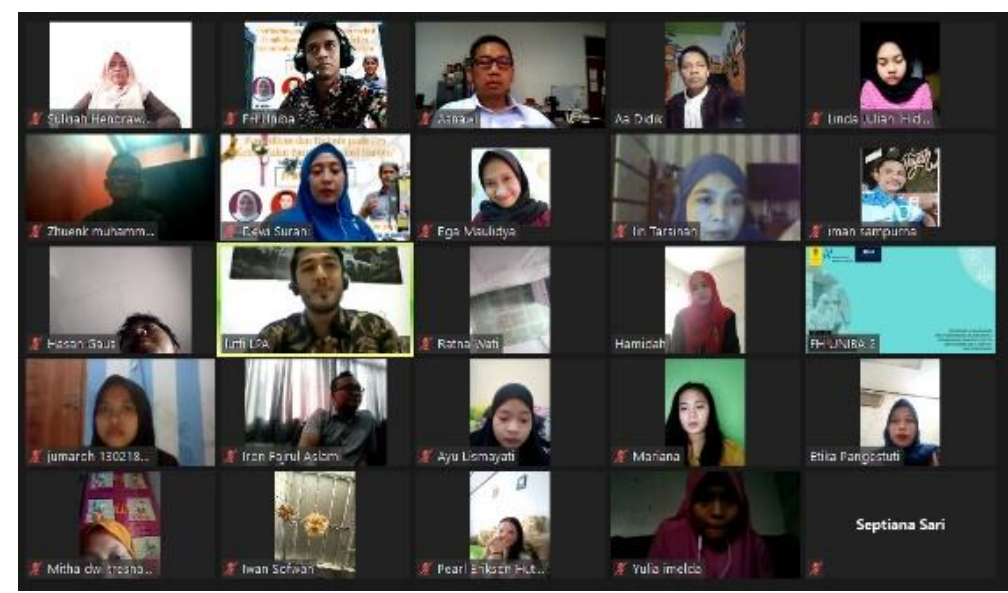

Gambar 3 Suasana Kegiatan Webinar Pengabdian Masyarakat

Oleh karena dengan diberikan edukasi melalui webinar oleh munculnya pemahaman pentingnya ketahana keluarga karena idealnya dalam pembelajara daring di pandemi Covid-19 saat ini keluarga mempunyai kemampuan antara lain:

1). Pengasuhan psikologis

Untuk pengasuhan psikologis ini orang tua bisa memperkuat psikologis anak dengan memberikan contoh dalam mengendalikan diri dan emosi mmepunyai rasa percaya diri ketika berinteraksi dengan orang lain, memperkuat komitmen untu terus belajar dan mengembangkan diri. Orang tua sebagai pendidik dan pengasuh harus mengingatkan anak tetap pentingnya belajar dan sungguh-sungguh belajar meskipun pembelajaran secara daring dari rumah.

2). Pengasuhan berbasih Hak anak

Orangtua harus memenuhi hak anak serta memberikan perlindungan terhadap anak yang meliputi tidak membeda-bedakan, mengutamakan kepentingan terbaik anak, hidup, tumbuh kembangannya serta partisipasi. Hal tersebut bertujuan untuk memenuhi kebutuhan anak akan kasih, keselamatan dan kesejahteraan. 
3). Pengenalan dan pembentukan Karakter anak

Untuk menghindari pengaruh negatif digital karena dalam pembelajaran daring anak intens menggunakan handphone dan akses internet, maka orang tua sebaiknya mengenali karakter anak dan membentuk karakter anak untuk mencegah pengaruh negatif tersebut serta mendoorng munculnya konten positif bagi anak dan terus menggali potensi anak untuk dikembangkan.

4). Komunikasi dan koordinasi yang berkelanjutan dengan semua pihak

Orang tua harus mampu berkomunikasi dan berkoordinasi yang berkelanjutan dengan semua pihak baik dengan sekolah, guru kelas dan guru mata belajar guna mendapatkan infomasi guna kepentingan pendidikan anaknya

5). Terciptanya atmosfer keluarga

Terciptanya situasi dan keadaan yang tenang, harmonis, adanya kasih sayang, dukungan serta perhatian antar anggota keluarga apalagi dalam pembelajaran dari dimasa pandemi seperti saat ini. Atmosfer keluarga yang positif akan mendukung proses pembelajaran daring di rumah menjadi lebih optimal.

6). Literasi Digital.

Orang tua harus melek dan mampu akan internet dan semua yg serba virtual acces, karena akan menjadi hambatan sendiri bagi berjalannya pembelajaran daring apabila oran tua tidak mempunyai literasi digital yang bagus.

7). Kemampuan ekonomi

Kesiapan keluarga dalam belajar dari rumah juga sangat ditunjang akan kemampuan ekonomi orang tua. Kemampuan ekonomi merupakan faktor eksternal yang berasal dari luar individu tersebut. karena pembelajaran online/blended learning membutuhkan support fasilitas tidak hanya kuota tapi perangkat seperti komputer, laptot, dan android guna mengases kegiatan pembelajaran. Orang tua diharapkan dapat memberikan kemampuan ekonomi kepada anaknya apalagi pelaksanaan belajar dari rumah memakai platform online yang menuntut adanya fasilitas komputer, laptot maupun Handphone androit serta kuota internet. Ketersedian fasilitas pendukung dan akses tersebut bukan merupakan suatu masalah yang besar bagi keluarga yang mampu ekonominya tapi akan berbeda bagi keluarga yang tidak beruntung secara ekonmi. Apabila kemampuan ekonomi dari orang tua semakin baik, maka akan berdampak baik pula bagi proses dan hasil belajar siswa. (Susanti \& Wahyudin, 2013).

\section{SIMPULAN}

Berdasarkan pengamatan dari jalannya webinar kegiatan pengabdian masyarakat baik dalam penyampaian materi edukasi, diskusi serta tanya jawab, dapat disimpulkan sebagai berikut:

1). Pembelajaran daring dalam masa pandemi covid-19 membutuhkan peran dan kesiapan keluarga, khususnya orang tua.

2). Peran orang tua akan optimal guna mendukung pembelajaran daring apabila adanya kapabilitas keluarga seperti: pengasuhaan psikologis, pengasuhan berbasis hak anak, pengenalan dan pembentukan karakter anak, komunikasi dan koordinasi yang berkelanjutan, terciptanya atmosfer keluarga yang positif, kemampuan digital dan ekonomi 


\section{DAFTAR PUSTAKA}

Amalia, L. (2018). Millenial Di Era Globalisasi Sebagai Salah Satu Pondasi Ketahanan Nasional. Jurnal Kesejahteraan Keluarga Dan Pendidikan, 05(02), 159-172

Amanah, S. (2020). Orang Tua Hebat: Pandemi Covid-19 menciptakan atmosfer keluarga yang kolaboratif. Jamberita.Com.

https://jamberita.com/read/2020/04/17/5958376/orang-tua-hebat-pandemicovid19-menciptakan-atmosfer-keluarga-yang-kolaboratif

Baker, William E. Dan James M. Sinkula. (2005). Environmental Marketing Strategy and Firm Performance: Effects on New Product Performance and Market Share. Academy of Marketing Science 33 (4):461-475. Banerjee, S., dan D. A.

Bangun, D. (2012). Hubungan Persepsi Siswa Tentang Perhatian Orang Tua, Kelengkapan Fasilitas Belajar, Dan Penggunaan Waktu Belajar di Rumah dengan Prestasi Belajar Ekonomi. Jurnal Ekonomi Dan Pendidikan, 5(1), 74-94. https://doi.org/10.21831/jep.v5i1.604

Hanh, T. N. (2007). Hidup Bersama Secara Harmonis. Ian Dharma dan Pustaka Dharmajala.

Prodjo, W. A. (2020). Apa itu Belajar dari Rumah? Melihat Kembali Konsep Awal... Artikel ini telah tayang di Kompas.com dengan judul "Apa itu Belajar dari Rumah? Melihat Kembali Konsep Awal...", https:/ledukasi.kompas.com/read/2020/04/14/163041771/apa-itu-belajar-darirumah-me. Edukasi.Kompas.Com.

Susanti, E., \& Wahyudin, A. (2013). Economic Education Analysis Journal. 2(1), 1823. 